\title{
Polymerization and Copolymerization of Olefins and Acrylates by Bisbenzimidazole Copper Catalysts
}

\author{
Robert T. Stibrany*, Donald N. Schulz, Smita Kacker, Abhimanyu O. \\ Patil, Lisa S. Baugh, Steven P. Rucker, Stephen Zushma, Enoch Berluche, \\ Joseph A. Sissano \\ Corporate Strategic Research, ExxonMobil Research and Engineering Co. \\ 1545 Route 22 East, Annandale NJ 08801
}

\section{Supporting Information}

Table of Contents

$\begin{array}{cl}\text { Page } & \\ 1 & \text { index } \\ 2-8 & \text { Preparation of } \mathbf{1 a}-\mathbf{7} \mathbf{b} \\ 8-9 & \text { X-ray crystallography } \\ 10 & \text { ORTEP 2 } \\ 11 & \text { ORTEP 3b } \\ 12 & \text { ORTEP 5 } \\ 13 & \text { ORTEP 5·H } \mathbf{2} \mathbf{O} \\ 14 & \text { ORTEP 6b } \\ 15 & \text { ORTEP 7a-1,2-dichlorobenzene } \\ 16-17 & \text { Polymerization studies } \\ 18 & \text { Figure 1 and Figure 2 } \\ 19 & \text { Epimerization and EPR studies } \\ 20 & \text { References }\end{array}$




\section{Synthetic Experimental Section}

All reagents were used as received or purified by standard methods. ${ }^{1}$ NMR spectra were recorded using a Bruker AVANCE 400 Ultrashield spectrometer. Melting points were determined with a hot-stage apparatus and are uncorrected. Infrared spectra were measured using a Mattson Galaxy Series 5000 spectrophotometer. Densities of the

crystalline products were measured by flotation. TLC was performed using $60 \AA$ silica gel on glass with a $254 \mathrm{~nm}$ fluorescent indicator. Preparation of $\mathbf{1}$ - $\mathbf{4}$ were performed under nitrogen. The preparation of $\mathbf{5} \mathbf{- 7}$ were performed with the exclusion of water.

\section{Synthesis of Compounds 1-7.}

1,1'-bis(1-hydrobenzimidazol-2-yl)]carbinol, (1a). A mixture of $8.00 \mathrm{~g}$ of (66.6 mmol) of hydroxypropanedioic acid and $14.41 \mathrm{~g}$ (133.3 mmol) of 1,2-phenylene diamine in 90 $\mathrm{mL}$ of $4 \mathrm{~N}$ hydrochloric acid was refluxed for $18 \mathrm{~h}$. The reaction mixture was cooled and the $\mathrm{pH}$ was adjusted to about 8 with ammonium hydroxide to give a pale-green solid. The solid was collected by filtration, washed with water, and dried in a vacuum oven to give of 1,1'-bis(1-hydrobenzimidazol-2-yl)]carbinol as an amorphous solid. Yield: $8.85 \mathrm{~g}$, $50.3 \%$. mp $198{ }^{\circ} \mathrm{C}$ (soften) $328{ }^{\circ} \mathrm{C}$ (melt) $-{ }^{1} \mathrm{H}$ NMR $\left(\mathrm{CD}_{3} \mathrm{SO}_{2} \mathrm{CD}_{3}\right): \delta=7.73$ (d, $J=7.5$ $\mathrm{Hz}, 2 \mathrm{H}), 7.50(\mathrm{q}, J=3.5 \mathrm{~Hz}, 4 \mathrm{H}), 7.34(\mathrm{t}, J=7.0 \mathrm{~Hz}, 2 \mathrm{H}), 7.22(\mathrm{t}, J=7.0 \mathrm{~Hz}, 2 \mathrm{H}), 7.16(\mathrm{q}$, $J=3.0 \mathrm{~Hz}, 4 \mathrm{H}), 6.97(\mathrm{~d}, J=7.5 \mathrm{~Hz}) .{ }^{13} \mathrm{C} \mathrm{NMR}\left(\mathrm{CD}_{3} \mathrm{SO}_{2} \mathrm{CD}_{3}\right): \delta=153.2,141.0,138.7$, $130.6,130.4,130.0,128.9,127.4,122.1,115.2 . R_{f}=0.30$ (ethyl acetate).

1,1'bis(1-hydrobenzimidazol-2-yl)methane, (1b). In a $1 \mathrm{~L}$ round bottom flask, $24.06 \mathrm{~g}$ $(0.23 \mathrm{~mol})$ of malonic acid, $50.00 \mathrm{~g}$ of $(0.46 \mathrm{~mol})$ 1,2-phenylene diamine, and $85 \mathrm{~g}$ of polyphosphoric acid were added sequentially. The mixture was heated at $210^{\circ} \mathrm{C}$ using a Dean-Stark trap for $3.5 \mathrm{~h}$ with stirring. The mixture was cooled to $150{ }^{\circ} \mathrm{C}$ and then poured into $1 \mathrm{~L}$ of water. A blender was used to grind the slurry. The mixture was then neutralized to $\mathrm{pH} 8$ with ammonium hydroxide. The solid was collected by filtration and repeatedly washed with water. The solid was dried to constant weight using vacuum at 80 ${ }^{\circ} \mathrm{C}$ for 24 h. Yield: $33.1 \mathrm{~g}, 58 \%$. mp $331{ }^{\circ} \mathrm{C}$ (dec.); ${ }^{1} \mathrm{H}$ NMR $\left(\mathrm{CD}_{3} \mathrm{SO}_{2} \mathrm{CD}_{3}\right): \delta=7.53(\mathrm{q}, J$ 
$=3.1 \mathrm{~Hz}, 4 \mathrm{H}), 7.16(\mathrm{q}, J=3.1 \mathrm{~Hz}, 4 \mathrm{H}), 4.54(\mathrm{~s}, 2 \mathrm{H}), 2.51(\mathrm{~s}, 2 \mathrm{H}) ;{ }^{13} \mathrm{C} \mathrm{NMR}\left(\mathrm{CD}_{3} \mathrm{SO}_{2} \mathrm{CD}_{3}\right)$ $\delta 150.6,139.1,121.9,115.1,29.7$. $R_{f}=0.28$ (ethyl acetate), FD MS 248.2. IR $(\mathrm{KBr}$ pellet, $\mathrm{cm}^{-1}$ ) 1622, 1590, 1544, 1530, 1487, $1435 \mathrm{~s}, 1309,1271 \mathrm{~s}, 1031 \mathrm{~s}, 999,738 \mathrm{~s}, 618$, 466. Anal. Calcd for N 22.57, H 4.87, C 72.56. Found: N 22.57, H 4.86, C 72.36.

2,2'-bis[2-(1-hydrobenzimidazol-2-yl)]biphenyl, (1c). In a 1 L round bottom flask, $35.00 \mathrm{~g}(0.145 \mathrm{~mol})$ of biphenyl-2,2'-dicarboxylic acid, $31.25 \mathrm{~g}$ of $(0.289 \mathrm{~mol}) 1,2-$ phenylene diamine, and $50 \mathrm{~g}$ of polyphosphoric acid were added sequentially. The mixture was heated at $210{ }^{\circ} \mathrm{C}$ using a Dean-Stark trap for $3.5 \mathrm{~h}$ with stirring. The mixture was cooled to $150{ }^{\circ} \mathrm{C}$ and then poured into $1 \mathrm{~L}$ of water. A blender was used to grind the slurry. The mixture was then neutralized to $\mathrm{pH} 8$ with ammonium hydroxide. The solid was collected by filtration and repeatedly washed with water. The solid was dried to constant weight using vacuum at $80{ }^{\circ} \mathrm{C}$ for $24 \mathrm{~h}$. Yield: $53.98 \mathrm{~g}, 96 \%$. mp $295{ }^{\circ} \mathrm{C}-{ }^{1} \mathrm{H}$ $\operatorname{NMR}\left(\mathrm{CD}_{3} \mathrm{SO}_{2} \mathrm{CD}_{3}\right): \delta=7.73(\mathrm{~d}, J=7.5 \mathrm{~Hz}, 2 \mathrm{H}), 7.50(\mathrm{q}, J=3.5 \mathrm{~Hz}, 4 \mathrm{H}), 7.34(\mathrm{t}, J=7.0$ $\mathrm{Hz}, 2 \mathrm{H}), 7.22(\mathrm{t}, J=7.0 \mathrm{~Hz}, 2 \mathrm{H}), 7.16(\mathrm{q}, J=3.0 \mathrm{~Hz}, 4 \mathrm{H}), 6.97(\mathrm{~d}, J=7.5 \mathrm{~Hz}) .{ }^{13} \mathrm{C} \mathrm{NMR}$ $\left(\mathrm{CD}_{3} \mathrm{SO}_{2} \mathrm{CD}_{3}\right): \delta=153.2,141.0,138.7,130.6,130.4,130.0,128.9,127.4,122.1,115.2$. $R_{f}=0.36$ (ethyl acetate) - FD MS 387.3. IR $\left(\mathrm{KBr}\right.$ pellet, $\left.\mathrm{cm}^{-1}\right) 1709 \mathrm{~m}, 1621 \mathrm{~m}, 1431 \mathrm{~s}$, 1369 w, 1274 m, 744 s, 531 w, 429 w. Anal. Calcd for N 14.50, H 4.69, C 80.81. Found: N 14.41, H 4.79, C 80.65.

1,1'-bis(1-methylbenzimidazol-2-yl)-1"-(methoxy)ethane, (2). A $1.00 \mathrm{~g}(3.8 \mathrm{mmol})$ quantity of 1a was suspended in $50 \mathrm{~mL}$ of purified tetrahydrofuran. Sodium hydride $80 \%$ dispersion in mineral oil, $0.68 \mathrm{~g}(22.8 \mathrm{mmol})$ was slowly added to the suspension and was stirred for $0.5 \mathrm{~h}$. A $2.16 \mathrm{~g}(15.2 \mathrm{mmol})$ quantity of iodomethane was added dropwise and allowed to stir for $18 \mathrm{~h}$. The reaction mixture was quenched with saturated aqueous sodium sulfate solution. Tetrahydrofuran was then removed by rotory-evaporation. The remaining oil was washed with water and separated with methylene chloride followed by chromatography. The 1,1'-bis(1-methylbenzimidazol-2-yl)-1"-(methoxy)ethane, 2, was recrystallized from a mixture of 2-propanol and cyclohexane to give $0.23 \mathrm{~g}$ of solid. Suitable single crystals were obtained by slow evaporation of an acetone solution of $\mathbf{2}$. Yield: 18.9\%. mp 194-195 ${ }^{\circ} \mathrm{C}$.; EI-MS 320; ${ }^{1} \mathrm{H}$ NMR $\left(\mathrm{CDCl}_{3}\right): \delta=7.81(\mathrm{~m}, 2 \mathrm{H}), 7.31(\mathrm{~m}$, $6 \mathrm{H}), 3.67(\mathrm{~s}, 6 \mathrm{H}), 3.27(\mathrm{~s}, 3 \mathrm{H}), 2.29(\mathrm{~s}, 3 \mathrm{H})$. 
1,1'bis(1-ethylbenzimidazol-2-yl)propane, (3a). A $19.10 \mathrm{~g}$ ( $0.077 \mathrm{~mol})$ quantity of $\mathbf{1 b}$ was placed in a $500 \mathrm{~mL}$ round bottom flask with a side arm. This was followed by the addition of $30 \mathrm{~mL}$ of purified dimethyl sulfoxide. The flask was fitted with a bubbler. Then under a flow of nitrogen $7.0 \mathrm{~g}$ of sodium hydride ( $80 \%$ dispersion in mineral oil) was added over one hour with stirring. Then $18.50 \mathrm{~mL}(0.231 \mathrm{~mol})$ of iodoethane was added dropwise over one hour. The reaction mixture was left stirring under nitrogen overnight. The reaction mixture was quenched with water and then an additional $150 \mathrm{~mL}$ of water was added. After stirring for one half hour a brown solid seperated from the solution. The solid was collected by filtration and repeatedly washed with water. The solid was dried in a vacuum oven for 24 hours at $60{ }^{\circ} \mathrm{C}$. The solid was dissolved in a sufficient amount of acetone to give a yellow-brown solution. Then enough cyclohexane was added to give a cloudy solution. The mixture was refluxed on a steam bath for 10 min. followed by immersion in an ice bath for $15 \mathrm{~min}$. After which a dark sticky precipitate formed. The precipitate was removed by filtration. The filtrate was concentrated to dryness under reduced pressure to give a very pale-pink solid. Yield: $18.91 \mathrm{~g}, 74 \%$. mp $178{ }^{\circ} \mathrm{C}$ (dec.); ${ }^{1} \mathrm{H}$ NMR $\left(\mathrm{CDCl}_{3}\right): \delta=7.80(\mathrm{~m}, 2 \mathrm{H}), 7.26(\mathrm{~m}, 6 \mathrm{H})$, $4.78(\mathrm{t}, J=7.9 \mathrm{~Hz}, 1 \mathrm{H}), 4.32(\mathrm{q}, J=7.3 \mathrm{~Hz}, 4 \mathrm{H}), 2.63(\mathrm{qt}, J=7.5 \mathrm{~Hz}, 2 \mathrm{H}), 1.12(\mathrm{t}, J=7.3$ $\mathrm{Hz}, 3 \mathrm{H}), 0.96(\mathrm{t}, J=7.2 \mathrm{~Hz}, 6 \mathrm{H}) .{ }^{13} \mathrm{C} \mathrm{NMR}\left(\mathrm{CDCl}_{3}\right): \delta=151.5,142.5,135.2,122.7$, 122.1, 119.6, 109.6, 42.4, 38.8, 24.9, 14.6, 12.7. $R_{f}=0.50$ (ethyl acetate), FD MS 332.2. IR ( $\mathrm{KBr}$ pellet, $\mathrm{cm}^{-1}$ ) 3054 w, 2969 w, 2935 w, 2871 w, 1612 w, 1460 s, 1405 s, 1372 m, 1330 m, 1259 m, 1127 m, 964 m, 750 s, 421 w. Anal. Calcd for N 16.85, H 7.28, C 75.87. Found: N 16.21, H 7.36, C 75.77.

1,1'bis(1-butylbenzimidazol-2-yl)pentane, (3b). A $23.00 \mathrm{~g}$ (0.093 mol) quantity of $\mathbf{1 b}$ was placed in a $300 \mathrm{~mL}$ round bottom flask with a side arm. This was followed by the addition of $25 \mathrm{~mL}$ of purified dimethyl sulfoxide. The flask was fitted with a bubbler. Then under a flow of nitrogen $6.0 \mathrm{~g}$ of sodium hydride (60\% dispersion in mineral oil) was added over one hour with stirring. Then $25.00 \mathrm{~mL}(0.220 \mathrm{~mol})$ of 1-iodobutane was added dropwise over one hour. The reaction mixture was left stirring under nitrogen for 48 hours. The reaction mixture was quenched with water and then an additional $400 \mathrm{~mL}$ of water was added. After stirring for one half hour a biphasic solution was obtained. The 
organic layer was extracted with cyclohexane and was washed with water. The volatiles were removed under reduced pressure to leave a dark oil. The oil was chromatographed on silica gel with methylene chloride as the eluent. The solvent was removed under reduced pressure to give a very pale-pink oil which crystallized upon standing. Suitable single crystals were obtained by slow evaporation of a methylene chloride solution of $\mathbf{3 b}$. Yield: $20.44 \mathrm{~g}, 67 \%$. mp 82-83 ${ }^{\circ} \mathrm{C}-{ }^{1} \mathrm{H}$ NMR $\left(\mathrm{CDCl}_{3}\right): \delta=7.79(\mathrm{~m}, 2 \mathrm{H}), 7.24(\mathrm{~m}, 6 \mathrm{H})$, $4.88(\mathrm{t}, J=7.9 \mathrm{~Hz}, 1 \mathrm{H}), 4.16(\mathrm{~d} \mathrm{sp}, J=5.0 \mathrm{~Hz}, J=40.9 \mathrm{~Hz}, 4 \mathrm{H}), 2.59(\mathrm{~m}, 2 \mathrm{H}), 1.44(\mathrm{~m}$, $4 \mathrm{H}), 1.16(\mathrm{~m}, 4 \mathrm{H}), 1.10(\mathrm{~m}, 2 \mathrm{H}), 0.99(\mathrm{~m}, 2 \mathrm{H}), 0.89(\mathrm{t}, J=6.8 \mathrm{~Hz}, 3 \mathrm{H}), 0.61(\mathrm{t}, J=7.0 \mathrm{~Hz}$, $6 \mathrm{H}) .{ }^{13} \mathrm{C} \mathrm{NMR}\left(\mathrm{CDCl}_{3}\right): \delta=151.8,142.4,135.6,122.6,122.0,119.6,109.7,44.0,40.9$, $31.5,31.2,30.1,22.5,20.0,14.0,13.4 .-R_{f}=0.73$ (ethyl acetate) - FD MS 416.1, IR $\left(\mathrm{KBr}\right.$ pellet, $\left.\mathrm{cm}^{-1}\right) 3050 \mathrm{~m}, 2955 \mathrm{~m}, 2931 \mathrm{~m}, 2862 \mathrm{~m}, 1613 \mathrm{w}, 1501 \mathrm{~m}, 1458 \mathrm{~s}, 1400 \mathrm{~s}$, $1331 \mathrm{~m}, 1285 \mathrm{~m}, 1008 \mathrm{~m}, 933 \mathrm{~m}, 743 \mathrm{~s}, 434 \mathrm{w}$.

2,2'-bis[2-(1-ethylbenzimidazol-2-yl)]biphenyl - water, (4a-H2O). A $12.09 \mathrm{~g}(0.031$ mol) quantity of 1c was placed in a $250 \mathrm{~mL}$ round bottom flask with a side arm. This was followed by the addition of $100 \mathrm{~mL}$ of DMSO. The flask was fitted with a bubbler. Then under a flow of nitrogen $6.0 \mathrm{~g}$ of sodium hydride (80\% dispersion in mineral oil) was added over one hour with stirring. Then $5.20 \mathrm{~mL}(0.065 \mathrm{~mol})$ of iodoethane was added drop wise over one hour. The reaction mixture was left stirring under nitrogen overnight. The reaction mixture was quenched with water and then an additional $400 \mathrm{~mL}$ of water was added. After stirring for one half hour a pale-pink solid separated from the solution. The solid was collected by filtration and repeatedly washed with water. The solid was dried in a vacuum oven for 24 hours at $60{ }^{\circ} \mathrm{C}$. The solid was dissolved in $35 \mathrm{~mL}$ of methylene chloride to give a dark solution. Then $150 \mathrm{~mL}$ of pentane was added to give a cloudy solution. The mixture was placed in an ice bath for $30 \mathrm{~min}$. After which a dark sticky precipitate formed. The cloudy solute was decanted and the solvent was removed under reduced pressure to give a white crystalline solid. Yield: 13.12 g, 92\%. mp 166 (soften) $172{ }^{\circ} \mathrm{C}$ (melt) $-{ }^{1} \mathrm{H}$ NMR $\left(\mathrm{CDCl}_{3}\right): \delta=7.60(\mathrm{~d}, J=7.0 \mathrm{~Hz}, 2 \mathrm{H}), 7.41(\mathrm{~d}, J=6.5$ $\mathrm{Hz}, 2 \mathrm{H}), 7.30(\mathrm{~m}, 6 \mathrm{H}), 7.23(\mathrm{~m}, 6 \mathrm{H}), 3.67(\mathrm{brd} \mathrm{s}, 4 \mathrm{H}), 1.19(\mathrm{t}, J=7.0 \mathrm{~Hz}, 6 \mathrm{H}) .-{ }^{13} \mathrm{C} \mathrm{NMR}$ $\left(\mathrm{CDCl}_{3}\right): \delta=152.5,143.4,141.1,134.5,131.5,130.7,130.0,129.4,127.1,122.2,121.8$, 120.0, 110.0, 38.9, 14.8. $-R_{f}=0.62$ (ethyl acetate) - FD MS $442.0\left(\right.$ less $\left.\mathrm{H}_{2} 0\right)$, IR $(\mathrm{KBr}$ 
pellet, $\left.\mathrm{cm}^{-1}\right) 3378 \mathrm{~m}\left(\mathrm{H}_{2} \mathrm{O}\right), 3062 \mathrm{~m}, 2968 \mathrm{~m}, 2931 \mathrm{~m}, 2871 \mathrm{~m}, 1643 \mathrm{~s}, 1447 \mathrm{~s}, 1329 \mathrm{~s}$, 1276 s, 1128 m, 743 s, 476 w. Anal. Calcd for N 12.16, H 6.13, C 78.23. Found: N 11.91, H 6.14, C 79.16.

2,2'-bis[2-(1-octylbenzimidazol-2-yl)]biphenyl, (4b). In an argon glovebox, a $16.19 \mathrm{~g}$ $(0.042 \mathrm{~mol})$ quantity of $1 \mathrm{c}$ was placed in a $300 \mathrm{~mL}$ round bottom flask. A suspension was obtained after the addition of $60 \mathrm{~mL}$ of purified tetrahydrofuran. Then $3.2 \mathrm{~g}$ of sodium hydride powder was added over a half-hour period with stirring. After cooling $14.75 \mathrm{~mL}$ (0.082 mol) of 1-iodooctane was added dropwise over a half-hour period. After an hour a gray-white precipitate began to form. The mixture was allowed to stir an additional 12 hours. The reaction mixture was removed from the glove box and slowly quenched with water under nitrogen. The reaction mixture was extracted from water with methylene chloride. The methylene chloride was then dried over sodium sulfate and filtered. The methylene chloride was removed under high vacuum to give a pale-brown oil. Yield: $24.03 \mathrm{~g}, 95 \%$. oil - ${ }^{1} \mathrm{H}$ NMR $\left(\mathrm{CDCl}_{3}\right): \delta=7.58(\mathrm{~m}, 2 \mathrm{H}), 7.41(\mathrm{~m}, 2 \mathrm{H}), 7.31(\mathrm{~m}, 4 \mathrm{H})$, 7.23(m, 8H), 3.54(br s, 4H), 1.64(br s, 4H), 1.19(br m, $20 \mathrm{H}), 0.86(\mathrm{t}, J=6.9 \mathrm{~Hz}, 6 \mathrm{H})$. ${ }^{13} \mathrm{C} \mathrm{NMR}\left(\mathrm{CDCl}_{3}\right): \delta=151.6,142.3,140.0,133.7,130.4,129.7,128.5,128.4,126.0$, $121.1,120.7,118.9,109.0,43.1,30.7,28.4,28.1,27.9,25.6,21.6,13.1$ - $R_{f}=0.77$ (ethyl acetate), IR (film on KBr plates, cm ${ }^{-1}$ ) 3060 w, 2954 m. 2928 s, 2855 m, 1613 w, 1453 s, 1392 m, 1282 m, 1159 m, 744 s. Anal. Calcd for N 9.17, H 8.25, C 82.58. Found: N 9.07, H 8.25, C 82.11.

[1,1'-bis(1-methylbenzimidazol-2-yl)-1"'-(methoxy)ethane]copper(II) dichloride, (5). A solution of ethanol and triethylorthoformate was prepared by refluxing $30 \mathrm{~mL}$ of $100 \%$ ethanol and $4 \mathrm{~mL}$ of triethylorthoformate. A $245 \mathrm{mg}(1.82 \mathrm{mmol})$ quantity of $\mathrm{CuCl}_{2}$ (99.999\% Aldrich) was dissolved in the ethanol/triethylorthoformate mixture to form a yellow-green solution. After the addition of $584 \mathrm{mg}(1.82 \mathrm{mmol})$ of solid 2 an intensely yellow crystalline precipitate formed. The product 5 was collected by filtration and dried under vacuum. mp (stage) $262-263{ }^{\circ} \mathrm{C}$ (sharp, dec.) - IR (KBr pellet, $\mathrm{cm}^{-1}$ ) $3055 \mathrm{w}, 2933$ w, 1480 s, 1453 s, 1396 m, 1222 m, 1101 m, 1067 s, 759 s, 747 s. Anal. Calcd for Cu 14.00, Cl 15.61, H 4.40, C 50.19. Found: $\mathrm{Cu} 14.1, \mathrm{Cl} 15.87, \mathrm{H} 4.48, \mathrm{C} 50.11$.

[1,1'bis(1-ethylbenzimidazol-2-yl)propane]copper(II) dichloride, (6a). In an argon glovebox, a $8.11 \mathrm{~g}(0.0476 \mathrm{~mol})$ quantity of copper (II) dichloride dihydrate was 
dissolved in $500 \mathrm{~mL}$ of absolute ethanol. This was followed by the addition of $100 \mathrm{~mL}$ of TEOF. Then $14.37 \mathrm{~g}(0.0432 \mathrm{~mol})$ of $\mathbf{6}$ was added to the solution. The solution was heated at reflux for a half-hour. Upon cooling the bright yellow precipitate was collected by filtration and washed with TEOF followed by pentane. The solid was dried under high vacuum. Yield: $19.20 \mathrm{~g}$, 95\% . - mp (stage) $262{ }^{\circ} \mathrm{C}$ (sharp, dec.), (DSC) $266{ }^{\circ} \mathrm{C}$; $\mathrm{IR}(\mathrm{KBr}$ pellet, $\left.\mathrm{cm}^{-1}\right) 3053$ w, 2976 m, 2935 w, 2874 w, 1615 w, 1511 s, 1459 s, 1332 m, 1271 m, 1080 m, 974 m, 753 s, 560 w, 426 w. Anal. Calcd for N 12.00, H 5.18, C 54.02, Cu 13.61, Cl 15.19. Found: N 11.88, H 5.34, C 53.73, Cu 13.19, Cl 14.92.

[1,1'bis(1-butylbenzimidazol-2-yl)pentane]copper(II) dichloride, (6b). In an argon glovebox, a $5.41 \mathrm{~g}(0.0317 \mathrm{~mol})$ quantity of copper (II) dichloride dihydrate was dissolved in $300 \mathrm{~mL}$ of absolute ethanol. This was followed by the addition of $60 \mathrm{~mL}$ of TEOF. Then $12.02 \mathrm{~g}(0.0289 \mathrm{~mol})$ of 7 was added to the solution. The solution was heated at reflux for a half-hour. Upon cooling the bright yellow precipitate was collected by filtration and washed with TEOF followed by pentane. The solid was dried under high vacuum. Suitable single crystals of $\mathbf{6 b}$ were obtained by dissolving $250 \mathrm{mg}$ of amorphous 6b in a hot mixture of $0.5 \mathrm{~mL}$ of triethylorthoformate, $20 \mathrm{~mL}$ nitromethane, and $20 \mathrm{~mL}$ benzonitrile to give a clear yellow-green solution. An Erlenmeyer flask containing this mixture was sealed in a jar containing diethylether to allow vapor diffusion. Yield: 15.20 g, 96\%. mp (stage) $257^{\circ} \mathrm{C}$ (sharp, decomp.). IR (KBr pellet, $\mathrm{cm}^{-1}$ ) $3102 \mathrm{w}, 3060 \mathrm{w}, 3027$ w, 2959 s, 2930 s, 2871 m, 2859 m, 1616 w, 1513 s, 1460 s, 745 s, 502 w. Anal. Calcd for N 10.17, H 6.59, C 58.85, Cu 11.53, Cl 12.87. Found: N 10.16, H 6.72, C 58.79, Cu 11.43, $\mathrm{Cl} 12.92$.

rac-[2,2'-bis[2-(1-ethylbenzimidazol-2-yl)]biphenyl]copper(II) dichloride $\quad \cdot \quad$ 1,2dichlorobenzene], (7a) 1 1,2DCB. In an argon glovebox, a $5.30 \mathrm{~g}(0.0311 \mathrm{~mol})$ quantity of copper (II) dichloride dihydrate was dissolved in $200 \mathrm{~mL}$ of absolute ethanol. This was followed by the addition of $125 \mathrm{~mL}$ of TEOF. Then $12.50 \mathrm{~g}(0.0280 \mathrm{~mol})$ of 8 was added to the solution. The solution was heated at reflux for a half-hour. Upon cooling the bright yellow precipitate was collected by filtration and washed with TEOF followed by pentane. The solid was dried under high vacuum to give $11.54 \mathrm{~g}$ of yellow-orange solid. The solid was redissolved in a mixture of methylene chloride and 1,2-dichlorobenzene. This solution was placed in a dessicator containing pentane to allow vapor diffusion. 
After several days yellow-green prisms precipitate and are collected by filtration and washed with pentane and finally dried under ambient argon. This preparation also yielded suitable single crystals. mp (stage) $150{ }^{\circ} \mathrm{C}$ (opaque, loss of 1,2DCB) $300-301{ }^{\circ} \mathrm{C}$ (melt) IR (KBr pellet, cm $\left.{ }^{-1}\right) 3056$ w, 2989 w, 1612 w, 1470 s, 1419 s, 1345 m, 1273 m, 1135 m, 960 m, 752 s, 553 m, 424 w. Anal. (dried under high vacuum) Calcd for N 9.71, H 4.54, C 62.45, Cu 11.01, Cl 12.29. Found: N 9.44, H 4.66, C 61.65, Cu 10.72, Cl 12.18.

rac-[2,2'-bis[2-(1-octylbenzimidazol-2-yl)]biphenyl]copper(II) dichloride, (7b). In an argon glovebox, a $6.50 \mathrm{~g}(0.0382 \mathrm{~mol})$ quantity of copper (II) dichloride dihydrate was dissolved in $100 \mathrm{~mL}$ of absolute ethanol. This was followed by the addition of $100 \mathrm{~mL}$ of TEOF. Then $21.19 \mathrm{~g}(0.0347 \mathrm{~mol})$ of 9 was added to the solution. The solution was heated at reflux for a half-hour. Upon cooling the shimmering yellow precipitate was collected by filtration and washed with TEOF followed by pentane. The solid was dried under high vacuum. Yield: $13.02 \mathrm{~g}, 50 \% \mathrm{mp}$ (stage) $148{ }^{\circ} \mathrm{C}$ (soften) $152{ }^{\circ} \mathrm{C}$ (melt), (DSC) $156{ }^{\circ} \mathrm{C}\left(1^{\text {st }}\right.$ melt) $172{ }^{\circ} \mathrm{C}$ (recryst) $193{ }^{\circ} \mathrm{C}\left(2^{\text {nd }}\right.$ melt $) ;$ IR (KBr pellet, $\left.\mathrm{cm}^{-1}\right) 3060$ w, 2927 s, 2854 s, 1613 w, 1467 s, 1415 s, 1293 m, 1159 m, 1010 w, 746 s. Anal. Calcd for N 7.52, H 6.76, C 67.68, Cu 8.53, Cl 9.51. Found: N 7.46, H 6.76, C 67.43, Cu 8.46, $\mathrm{Cl}$ 9.42. $\mathrm{d}=1.07(1) \mathrm{g} \mathrm{cm}^{-3}$ (floatation in a mixture of cyclohexane/ $\mathrm{CF}_{2} \mathrm{ClCFCl}_{2}$ ).

X-ray Crystallography. For 2, 5, 6b, and 7a-1,2-dichlorobenzene, diffraction measurements were made on a Enraf-Nonius CAD-4 diffractometer, and the Nonius Structure Determination Package ${ }^{2}$ was used for data collection and processing. And Lorentz, polarization, decay, and absorption corrections ${ }^{3}$ were applied. Data for $\mathbf{3 b}, \mathbf{5} \cdot \mathbf{H}_{2} \mathbf{O}$, and 7b were collected using a Bruker SMART CCD area detector system using $\phi$ and $\omega$ scans. Cell parameters were determined using SMART software. ${ }^{4 a}$ The SAINT package ${ }^{4 a}$ was used for integration of data, Lorentz, polarization, and decay corrections, and for merging data. Absorption corrections were applied using SADABS. ${ }^{4 \mathrm{~b}}$ In all cases, graphite monochromated Mo K $\alpha$ radiation was used.

Structures were solved and refined on $\mathrm{F}^{2}$ using the SHELX system and all data. ${ }^{4 \mathrm{c}, \mathrm{d}}$ Partial structures were obtained by direct methods; the remaining non-hydrogen atoms in each structure were located using difference Fourier techniques. H atoms were located on difference Fourier maps or placed at calculated positions. For $\mathrm{H}$ atoms whose thermal 
parameters were not refined, isotropic temperature factors were set equal to $1.2-1.5 \mathrm{U}_{\mathrm{N}}$, where $\mathrm{N}$ is the atom bonded to $\mathrm{H}$. All structures were refined on $\mathrm{F}^{2}$ by using full-matrix least-squares techniques. Views of the structures were prepared using ORTEP32 for Windows. ${ }^{5}$ Additional details of the data collection, refinement, and metric parameters for the reported crystals studied are given in CIF format as supplementary material. Discussion of the extraordinary aspects of the structures follows.

Compound 2 crystallizes in the chiral space group P $2{ }_{1} 2{ }_{1} 2_{1}$. For light atom structures (all atoms $<\mathrm{Si}$ ) the absolute configuration can not be determined reliably and the Friedel pairs were merged accordingly.

In the structures of $\mathbf{3 b}$ and $\mathbf{6 b}$, the thermal motion of the alkyl chains is as expected, higher at the ends of the chains. This behavior has been observed in other structures. ${ }^{6}$ Without interatomic bonding interactions, such as hydrogen bonding, to stabilize the alkyl chains other contributing factors begin to predominate the thermal motion. Higher thermal motion in certain chains in the molecule over others of equal length is related to crystal packing forces. The molecular arrangement of the chains is such that the near neighbor interactions vary for each chain in the molecule. As near neighbor interactions lessen, the corresponding thermal motion of the chains increases. Also of note in $\mathbf{6 b}$ is the adoption of the cis configuration of the bridgehead alkyl chain to accommodate the $\mathrm{Cu}-\mathrm{Cl} 1$ interaction.

The structure of $\mathbf{5} \cdot \mathbf{H}_{2} \mathbf{O}$ is notable in a number of respects. Suitable single crystals were obtained by slow evaporation of a "wet" nitromethane solution of $\mathbf{5}$. First, this emphasizes the importance of preparing the copper pre-catalysts with steps to exclude the inclusion of water. Secondly, it is somewhat surprising that the water is included as a clathrate rather than coordinated to the metal center. This result might not be expected due to the propensity of $\mathrm{Cu}(\mathrm{II})$ to adopt a higher coordination number and disfavor a pseudotetrahedral coordination environment. Finally, the water molecules form hydrogen bonded dimers in the lattice. The water molecule, including both of the hydrogen atoms were located on difference Fourier maps and were refined. A O1w-H1w-O1w' angle of $155.85^{\circ}$ and a donor acceptor distance of $\mathrm{H} 1 \mathrm{w}-\mathrm{O} 1 \mathrm{w}$ ' distance of $2.4421 \AA$ is well within the accepted range of a hydrogen bond. This unusual clathrate may justify further structural characterization. 
Compound 7 forms a large number of clathrate structures. More than ten have already been identified. Again, as in 5, none of the clathrate molecules has been coordinated to the metal center. The ability to incorporate a large number guest molecules has been seen previously in such systems such the voluminous "porphyrin sponge" series. ${ }^{7}$ The 1,2-dichlorobezene clathrate was chosen for this study due to the ease in which a high yielding, pure product could be achieved. 


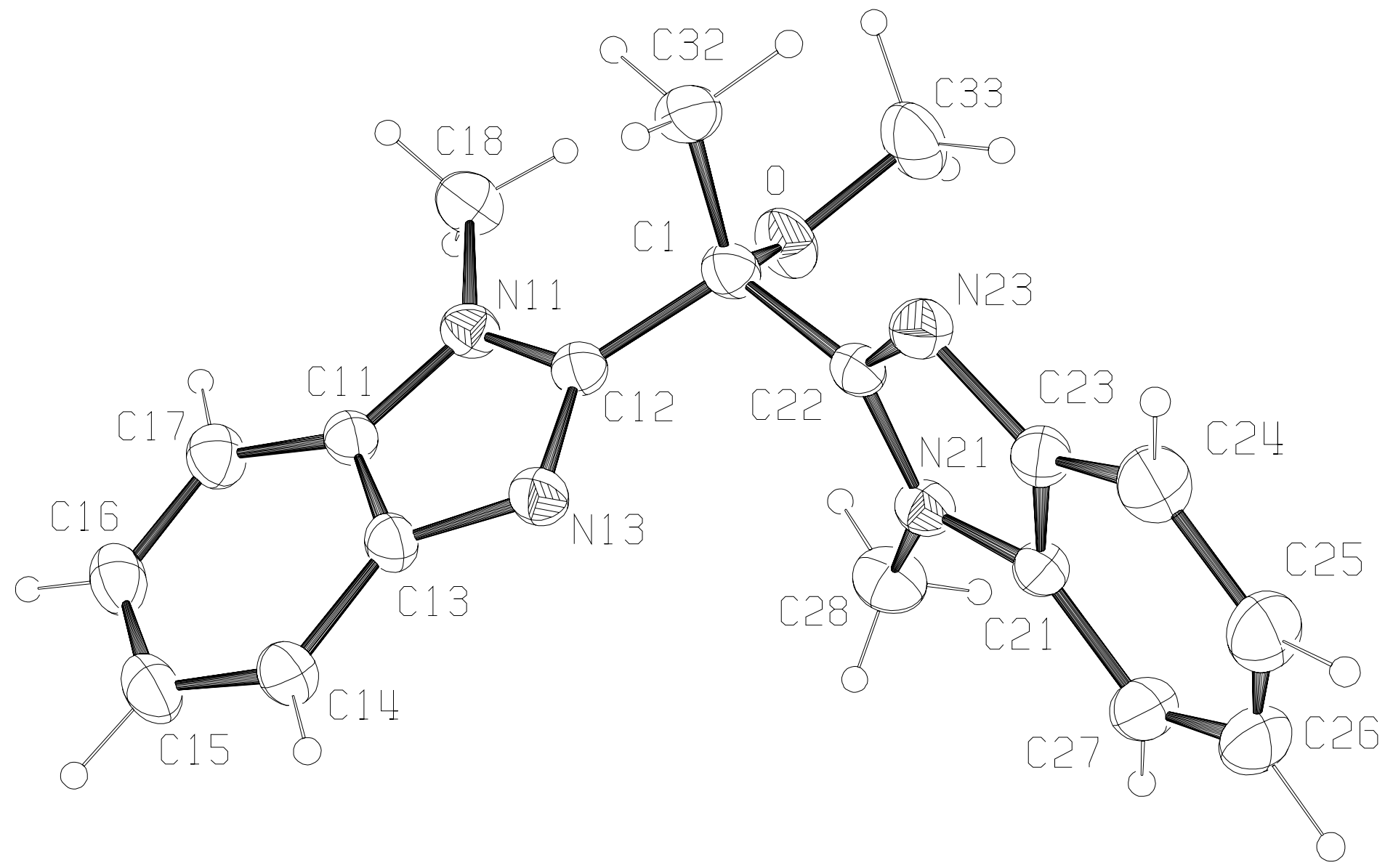

View $\left(\right.$ ORTEP $\left.^{5}\right)$ of 2 showing the atom numbering scheme. Thermal ellipsoids are drawn at the $25 \%$ level. 


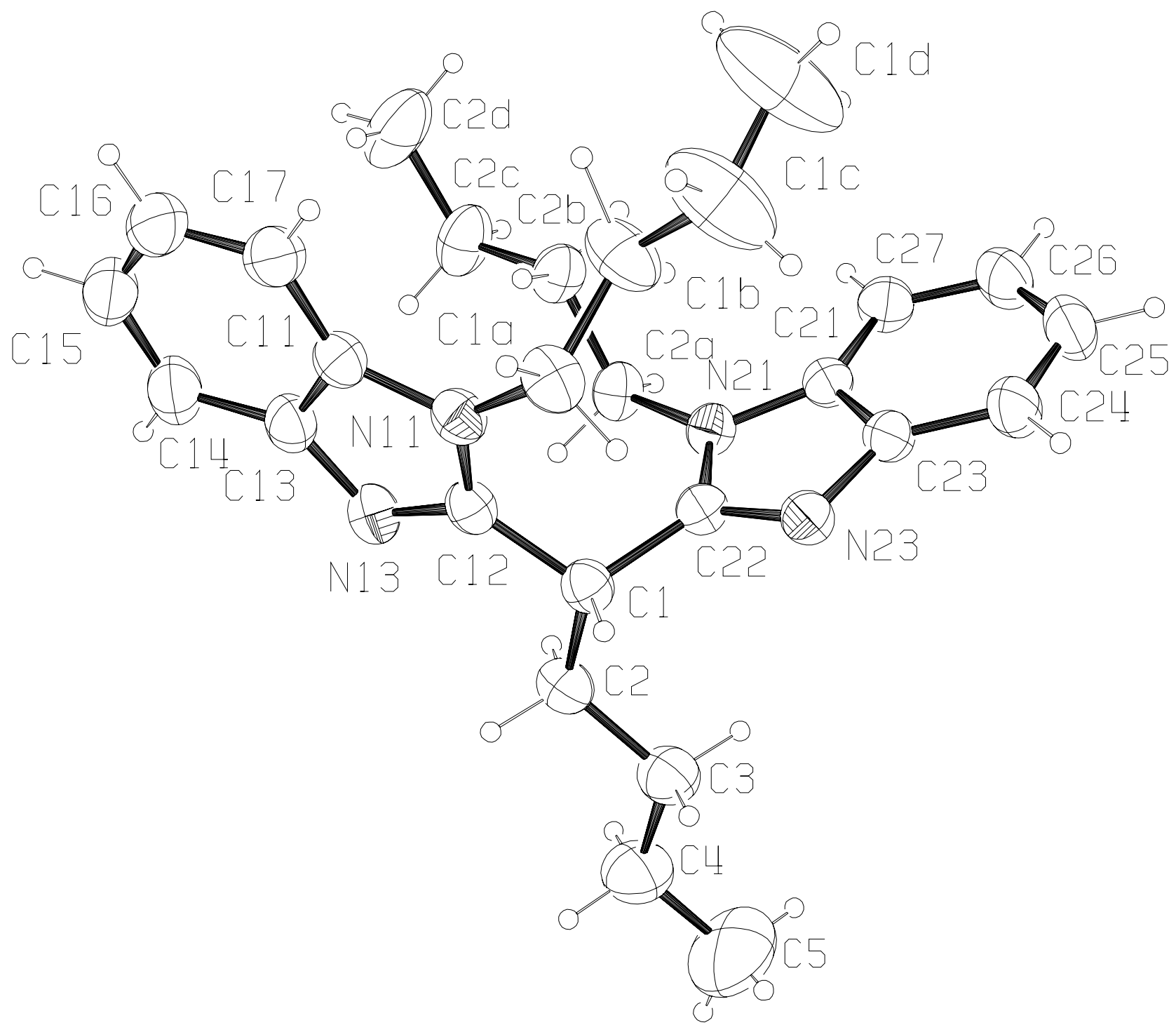

View $\left(\right.$ ORTEP $\left.^{5}\right)$ of $\mathbf{3 b}$ showing the atom numbering scheme. Thermal ellipsoids are drawn at the $25 \%$ level. 


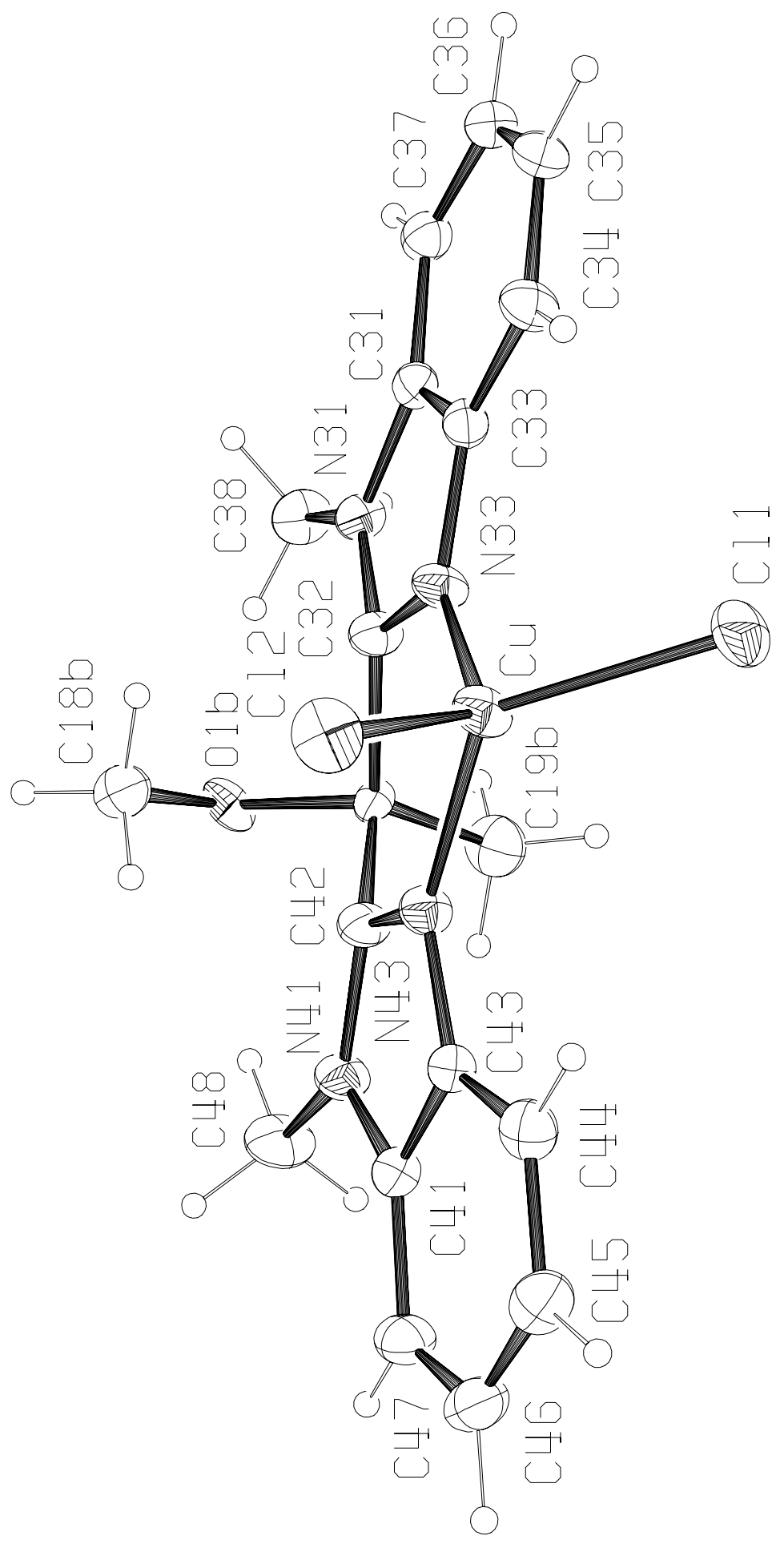

View $\left(\right.$ ORTEP $\left.^{5}\right)$ of $\mathbf{5}$ showing the atom numbering scheme. Thermal ellipsoids are drawn at the $25 \%$ probability level. 


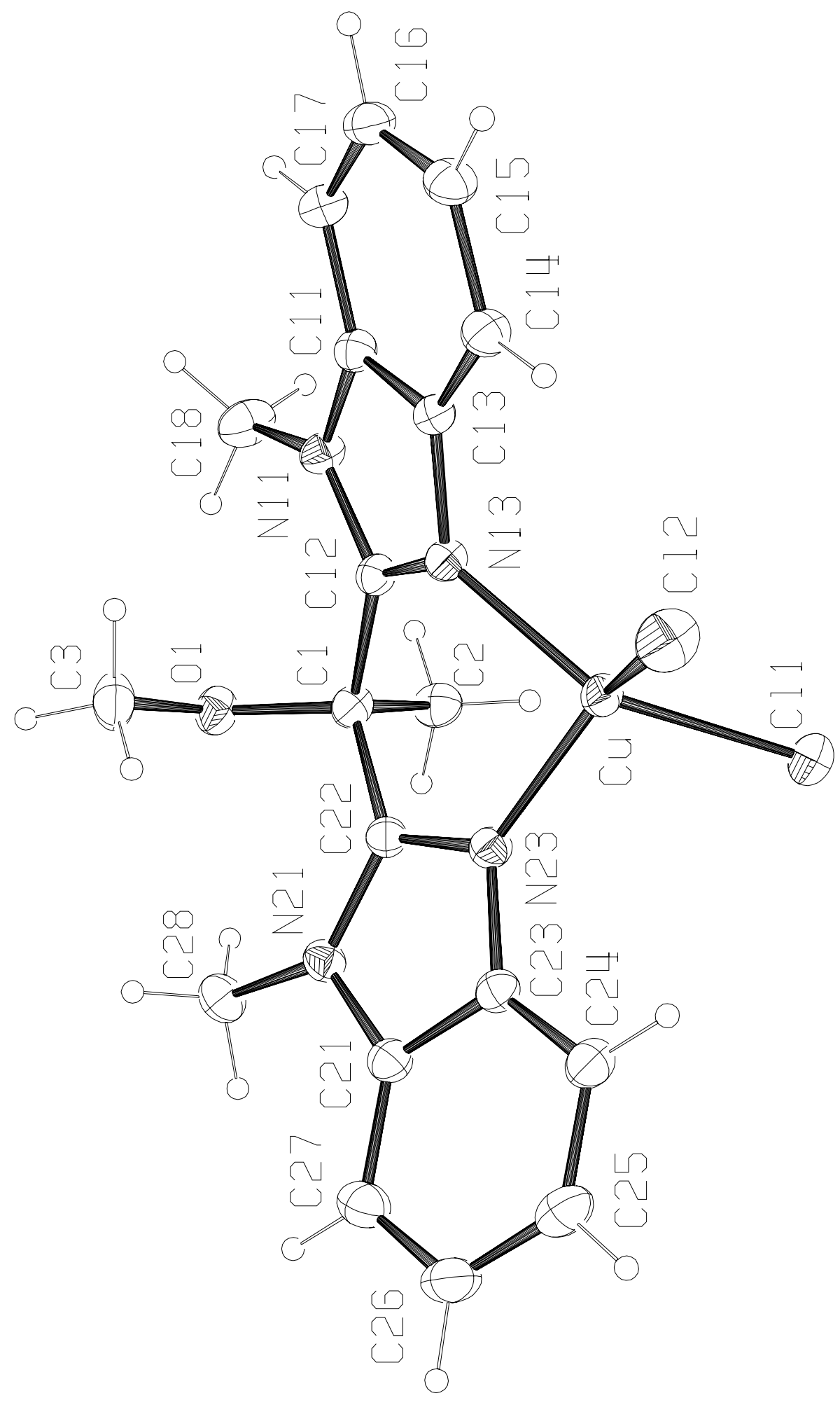

View $\left(\mathrm{ORTEP}^{5}\right)$ of $\mathbf{5} \cdot \mathrm{H}_{2} \mathrm{O}$ showing the atom-numbering scheme. Thermal ellipsoids are drawn at the $25 \%$ probability level. The lattice solvent was omitted for clarity. 


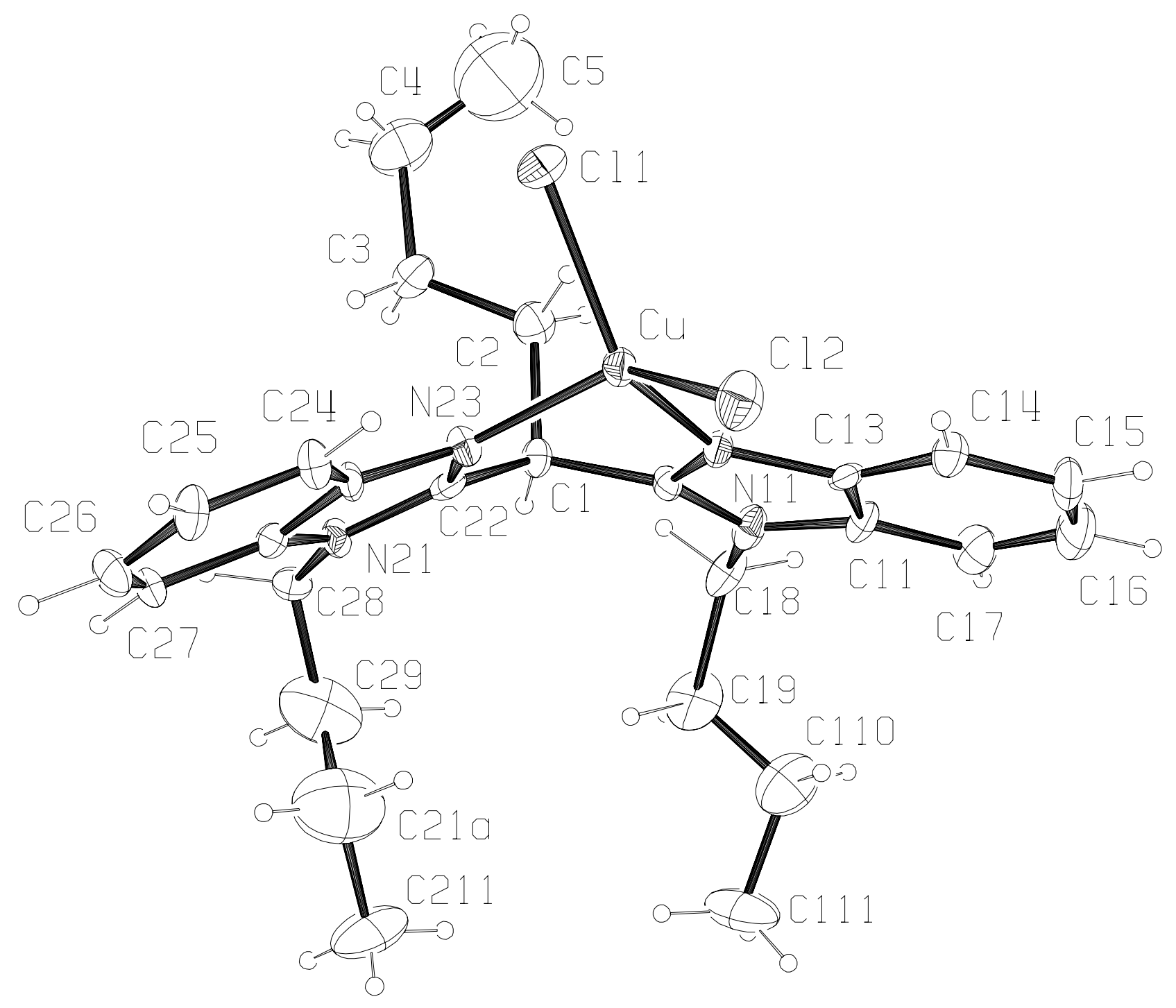

View $\left(\right.$ ORTEP $\left.^{5}\right)$ of $\mathbf{6 b}$ showing the atom numbering scheme. Thermal ellipsoids are drawn at the $25 \%$ probability level. 


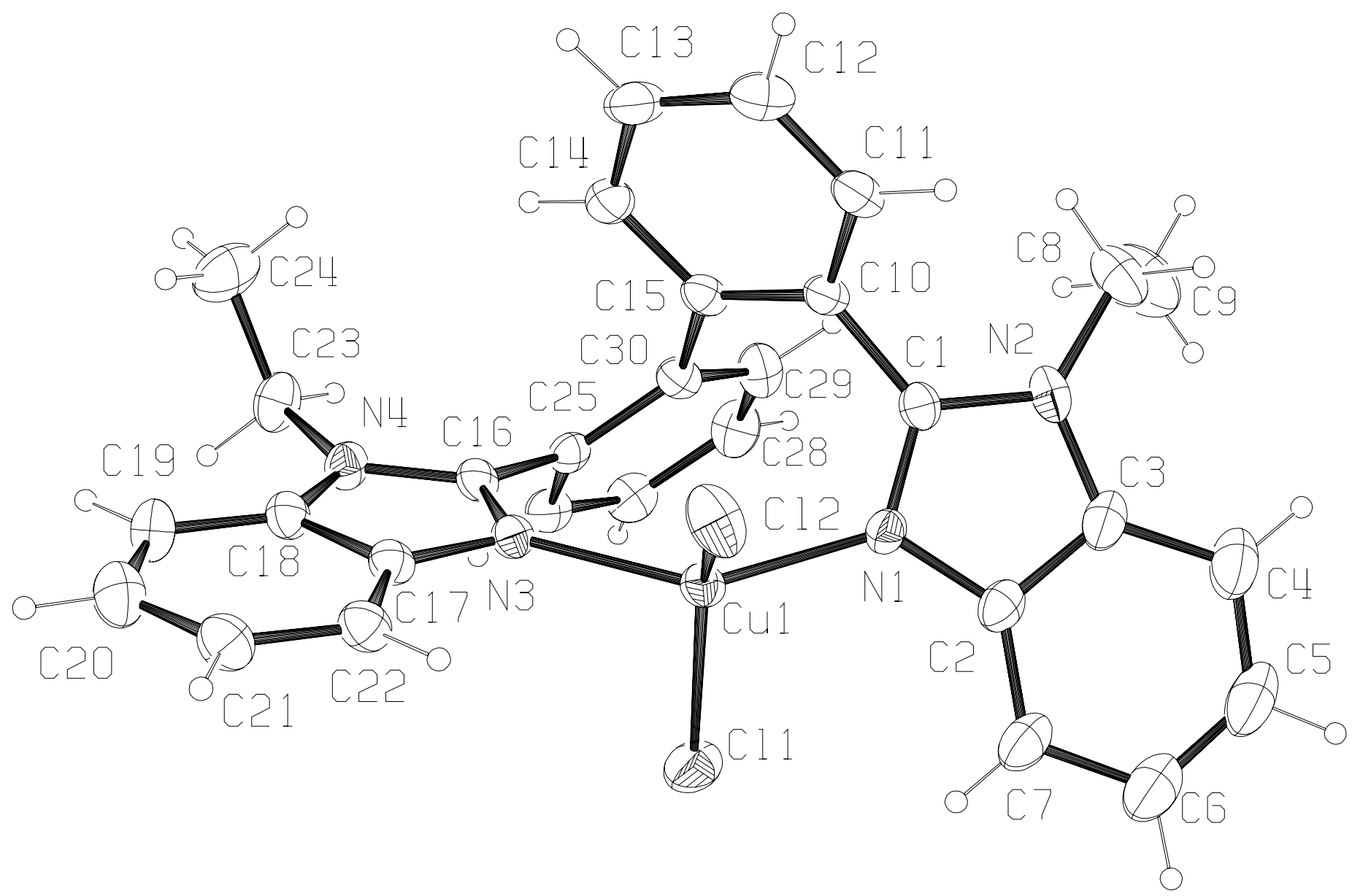

View $\left(\mathrm{ORTEP}^{5}\right)$ of $\mathbf{7 a} \cdot \mathbf{1 , 2}$-dichlorobenzene showing the atom numbering scheme.

Thermal ellipsoids are drawn at the $25 \%$ probability level. The lattice solvent was omitted for clarity. 


\section{Polymerization Studies}

All manipulations and polymerizations were performed under purified nitrogen or argon. Toluene was distilled under nitrogen from ( $\mathrm{Na} / \mathrm{ketyl})$ and stored under argon. Ethylene (99.995\%) was obtained form Matheson and was used as received. tert-Butyl acrylate could be used as received (10-100 ppm MEHQ inhibitor present), with added phenothiazine (100 ppm), or purified ${ }^{1}$ shortly before usage stored under argon, cold, and absent of light. 30\% MAO in toluene was obtained from Albemarle Corporation and was stored cold and absent of light. The tacticity of the homopolymers and the mole fraction content and triad distributions of the copolymers were determined using NMR techniques. NMR spectra were recorded using a Varian Unityplus 500 spectrometer and a Bruker AVANCE 400 Ultrashield spectrometer. Molecular weights for polyacrylate homo- and copolymers were measured on a Waters Associates gel permeation chromatography chromatograph equipped with three Polymer Laboratories mixed bed Type D columns and Peak Pro software at $30{ }^{\circ} \mathrm{C}$ in THF (1 mL / minute), versus polystyrene or poly(methyl methacrylate) standards. Dual DRI and UV-VIS (215 nm) detectors were used to determine the distribution of the acrylate monomer over the copolymer distribution. Molecular weights for polyethylenes were measured on a Waters Associates 150C High Temperature gel permeation chromatography chromatograph equipped with three Polymer Laboratories mixed bed Type B columns in 1,2,4trichlorobenzene at $135^{\circ} \mathrm{C}$ using triple detection (Precision Detector $15^{\circ}$ fixed-angle light scattering; Viscotek high-temperature viscometer; Waters $150{ }^{\circ} \mathrm{C}$ high-temperature DRI). Thermal characterization was obtained on a TA Instruments 2920 calorimeter using a scan rate of 10 degrees per minute; the second heat was analyzed from RT to $160^{\circ} \mathrm{C}$ for polyethylenes and from -110 to $160{ }^{\circ} \mathrm{C}$ for polyacrylates and copolymers.

Acrylate homopolymerizations were conducted using oven dried glassware. In the drybox, a flask was charged with a stirbar and $0.045 \mathrm{mmol}$ copper catalyst and $20 \mathrm{~mL}$ dry toluene. In a separate vial, $30 \mathrm{wt} \% \mathrm{MAO}$ solution in toluene diluted in $8 \mathrm{~mL}$ toluene, and the appropriate acrylate monomer was added. This solution was then added to the vessel containing the catalyst, and was rinsed with an additional $2 \mathrm{~mL}$ dry toluene. The rinse solvent was transferred to the catalyst container to make 30 total $\mathrm{mL}$ solvent. The vessel was sealed, completely covered in foil, and stirred at $25^{\circ} \mathrm{C}$ for $18 \mathrm{~h}$. A large excess of 
$5 \% \mathrm{HCl}$ in methanol was added, and this slurry was stirred until residual color disappeared. The insoluble polymer was collected by filtration, rinsed with clean methanol, and dried in a vacuum oven at $65^{\circ} \mathrm{C}$ overnight.

Copolymerizations of ethylene and acrylate were conducted using a $300 \mathrm{cc}$ glass lined autoclave. In the glovebox, the reactor was charged based on $0.045 \mathrm{mmol}$ of catalyst and a total of $70 \mathrm{~mL}$ dry toluene. Acrylate and $30 \% \mathrm{MAO}$ were added as in the homopolymerization. The reactor was assembled and sealed, and moved to an ethylene manifold. After purging the gas connections, the reactor was charged to 400 psi ethylene, and the air-driven stirrer was activated. The reactor was heated to $80{ }^{\circ} \mathrm{C}$ and the pressure was raised to 720 psig of ethylene. The ethylene was shut off and the polymerization was allowed to proceed at $80{ }^{\circ} \mathrm{C}$ for $18 \mathrm{~h}$, at approximately $350 \mathrm{rpm}$ stirring speed. Following cooling and depressurization, $5 \mathrm{cc}$ methanol was added via the syringe valve of the reactor as a quench. The reactor was opened and the contents poured into an excess of 50:50 methanol / 5-10\% aqueous $\mathrm{HCl}$. After stirring overnight, the insoluble polymer was collected by filtration and dried in a vacuum oven at $60-75^{\circ} \mathrm{C}$. 


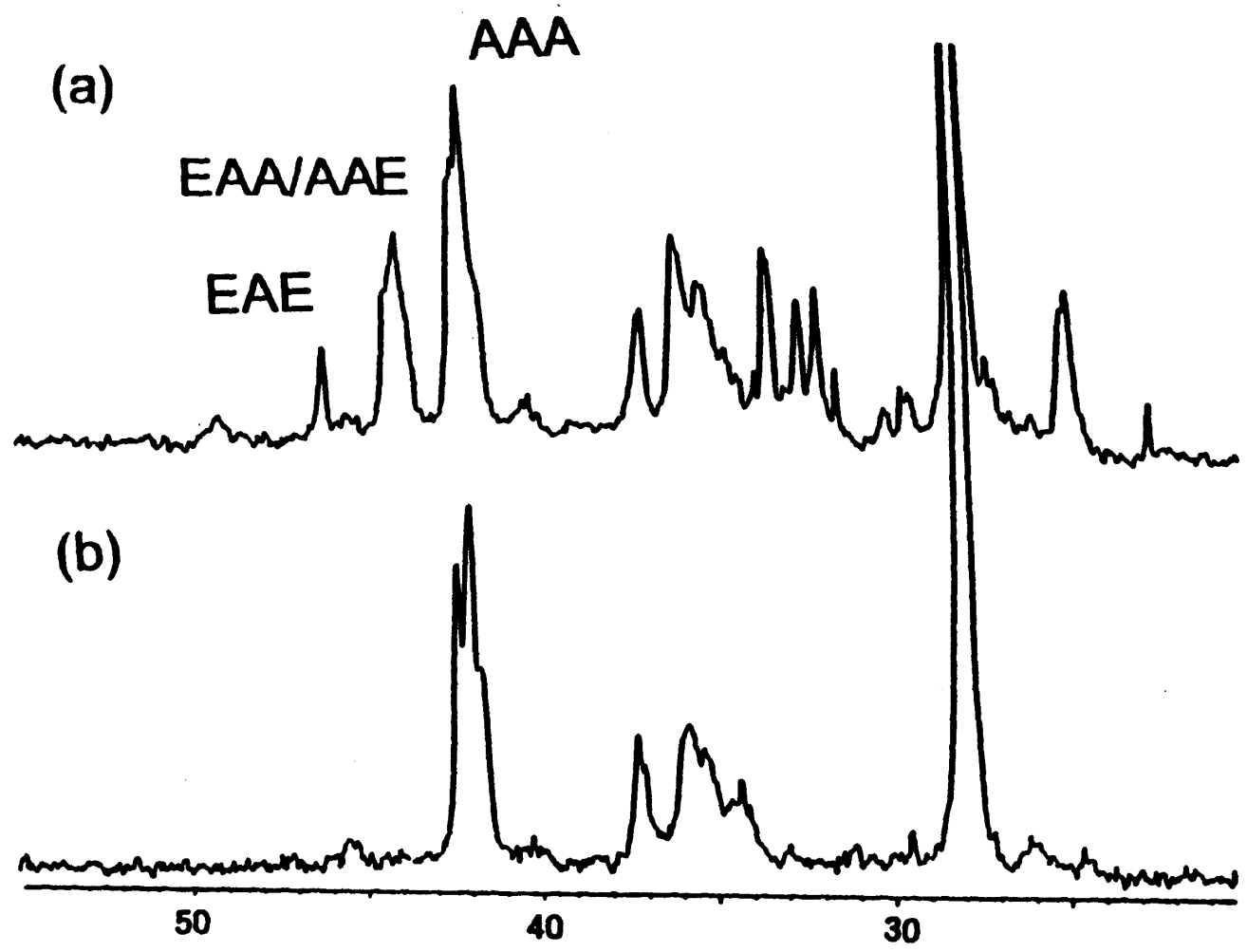

Figure 1. ${ }^{13} \mathrm{C}$ NMR spectra (a) ethylene/t-butyl acrylate copolymer indicating the EA triads and (b) $t$-butyl acrylate homopolymer.

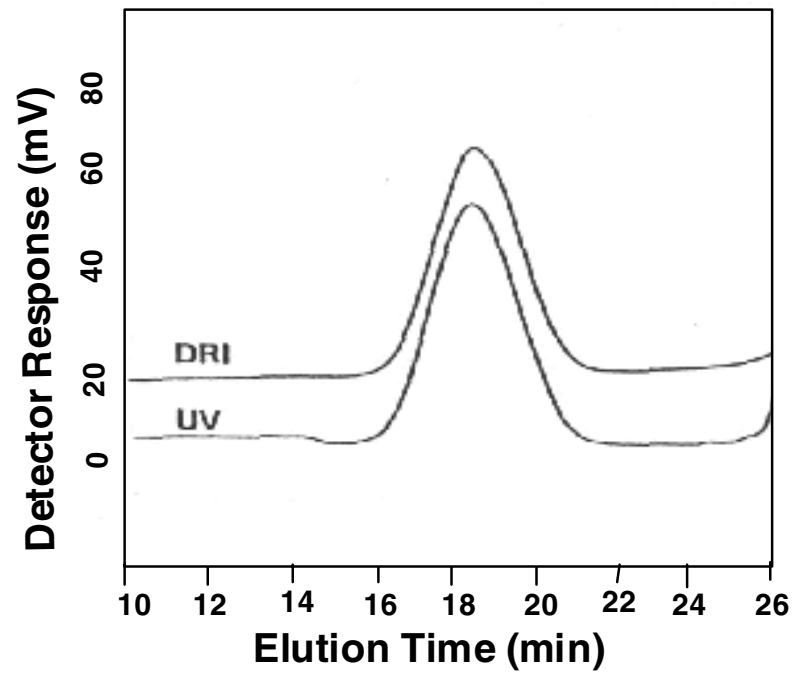

Figure 2. GPC of ethylene/t-butyl acrylate copolymer with DRI and UV detectors. 


\section{Epimerization Study}

Radically initiated poly $t$-BA was produced according to reference 20 . The polymer was produced on the $15 \mathrm{~g}$ scale using $3 \%$ benzoyl peroxide at $25{ }^{\circ} \mathrm{C}$. The characterization of the polymer compares well to that reported. The epimerization experiment was carried out identically to that of the $\mathrm{Cu}$-catalyzed homopolymerization of $t$-BA with the exception that radically produced poly $t$-BA $(3.0 \mathrm{~g})$ was introduced in place of $t$-BA monomer. After the attempted epimerization, the polymer remained unchanged within experimental error. This result argues that the tacticity of the $\mathrm{Cu}$ catalyzed polymer is significantly different than those produced radically. ${ }^{8}$ This also argues that the $\mathrm{Cu}$ catalyst is not simply acting as an epimerization catalyst to change the tacticity of a radically initiated polymer.

\section{EPR Studies}

EPR spectra were measured with a Varian E-12 spectrometer calibrated with a Hewlett-Packard Model 5245-L frequency counter and a DPPH crystal ( $\mathrm{g}=2.0036)$. Samples were taken of a typical $t$-BA homopolymerization described previously with catalyst 6a. In an Ar glovebox samples were taken at 0.25, 2, 6, and 24 hours. These samples were sealed under Ar in $3 \mathrm{~mm}$ quartz tubes. The spectra were measured at 296 and $77^{\circ} \mathrm{K}$. No detectable signal was observed in any of the samples. $\mathrm{Cu}$ ATRP polymerizations have been monitored by this technique with the observation of signals attributable to both $\mathrm{Cu}$ (II) and radicals. ${ }^{9}$ The absence of any signal indicates that if present, any $\mathrm{Cu}(\mathrm{II})$ and radical species are below $\sim 10^{-8} \mathrm{M}$. One of the samples was also examined at $353^{\circ} \mathrm{K}$ in order to look for any zero field splitting. Again, no signal could be found, eliminating, to a great extent, the possibility of $\mathrm{Cu}$ (II) dimers in any significant concetration. 


\section{References}

1. Perrin, D. D.; Armarego, W. L. F. Purification of Laboratory Chemicals Pergamon Press: New York, 1988.

2. Enraf-Nonius Structure Determination Package; Enraf-Nonius: Delft, Holland, 1985.

3. North, A. C. T.; Phillips, D. C.; Mathews, F. S. Acta Cryst. 1968, A24, 351-359.

4. (a) Bruker, 2000. SHELXTL (Version 6.10), Saint-Plus (Version 6.02) and SMARTWNT2000 (Version 5.622). Bruker AXS Inc., Madison, Wisconsin, USA. (b) Blessing, R. H. Acta Crystallogr. 1995, A51, 33-38. (c) Sheldrick, G. M. SHELXS-97. Acta Crystallogr. 1990, A46, 467-473. (d) Sheldrick, G. M. SHELXL-97. A Computer Program for the Refinement of Crystal Structures; University of Göttingen: Germany.

5. (a) Burnett, M. N.; Johnson, C. K. ORTEPIII, Report ORNL-6895; Oak Ridge National Laboratory, Tennessee, USA, 1996. (b) Farrugia, L. J. ORTEP32 for Windows, version 1.0.5; University of Glasgow, Scotland, 1997.

6. Stibrany, R. T.; Gorun, S. M. J. Organomet. Chem. 1999, 579, 217-221.

7. Byrn, M. P.; Curtis, C, J.; Goldberg, I.; Hsiou, Y.; Khan, S. I.; Sawin, P. A.; Tendick, K.; Strouse, C. E. J. Am. Chem. Soc. 1991, 113, 6549-6557.

8. Matyjaszewski, K. Macromolecules 1998, 31, 4710-4717.

9. Wang, A. R.; Zhu, S. Macromolecules 2002, 35, 9926-9933. 